\title{
A new species of Clinodiplosis Kieffer (Diptera, Cecidomyiidae) associated with Cecropia sp. (Urticaceae) in Brazil
}

\author{
Barbara Proença ${ }^{1,2}$ \& Valéria Cid Maia ${ }^{1,3}$ \\ 1 Universidade Federal do Rio de Janeiro (UFRJ), Museu Nacional, Departamento de Entomologia, Laboratório de Diptera. Rio de Janeiro, RJ, Brasil. \\ 2 ORCID: http://orcid.org/0000-0001-8081-0676. E-mail: bproenca28@gmail.com \\ ${ }^{3}$ ORCID: http://orcid.org/0000-0001-9396-5618. E-mail: maiavcid@acd.ufrj.br
}

\begin{abstract}
Clinodiplosis cecropiae Proença \& Maia a new species of Cecidomyiidae (Insecta: Diptera) is described and illustrated herein (larva, pupal exuviae, male and female). Samples of gall and host plant were collected in Amazon Rainforest areas, in Monte Negro municipality, Rondônia state, Brazil. The galler was obtained by rearing in laboratory and the specimens were mounted on microscope slides. The type material is deposited in the Cecidomyiidae collection of Museu Nacional/Universidade Federal do Rio de Janeiro. The new species induces globoid galls on leaf petiole of Cecropia sp. (Urticaceae). This is the first record of a Clinodiplosis species inducing galls on Urticaceae plants.
\end{abstract}

Key-Words. Amazon rainforest; Galling insect; Gall midge; Morphology and taxonomy.

\section{INTRODUCTION}

Clinodiplosis Kieffer, 1894 (Cecidomyiidi: Clinodiplosini) is a cosmopolitan genus, with 107 species described so far, most part being mycophagous, but some with phytophagous and galling inducer habits. In the Neotropical region most Clinodiplosis species are responsible for complex galls. In Brazil, there are 17 described species, the majority being gallers, mostly attacking the leaves of Amaranthacea, Asteraceae, Erythroxylaceae, Euphorbiaceae, Lamiaceae, Malpighiaceae, Melastomataceae, Moraceae, Myrtaceae, Rubiaceae, Sapindaceae and Verbenaceae (Gagné \& Jaschhof, 2017; Toma \& Maia, 2012).

The genus is characterized by the following characters: occipital process present; four-segmented palpi; wing with Rs weaker than $\mathrm{R} 1$, but evident, $\mathrm{R} 5$ joining $\mathrm{C}$ beyond the wing apex; tarsal claws simple or toothed on at least forelegs, bend near basal third or beyond midlength; empodia usually reaching to the bent of the claws or sometimes shorter; ovipositor short, barely protrusible; and female cerci separate; male cerci quadrate, secondarily lobed, acute or with oval margins; aedeagus is large and bulbous in some species (Gagné, 1994), and elongate and tapering to the apex in others as in Clinodiplosis cattleyae (Molliard, 1903) and C. agerati Maia, 2016.

The new species described here induces galls (Fig. 1) on leaves petioles of an unidentified spe- cies of Cecropia Loefl. (Urticaceae). Cecropia is an important genus of pioneer trees typical of large disturbed patches in Neotropical forests (Cornelis et al., 2005). In Brazil, this plant is commonly known as "embaúba" and can be found in all phytogeographical domains: Amazon rainforest, Caatinga (dry forest), Cerrado, Atlantic forest and Pantanal, except Pampa (Flora do Brasil, 2019).

The objective of this study was to describe a new species of Clinodiplosis associated with Cecropia sp., contributing to the knowledge of the Cecidomyiidae family in the Amazon rainforest. The Amazonian fauna of gall midges is one of the least known in Brazil, with only 13 recorded species so far (Gagné \& Jaschhof, 2017).

\section{MATERIAL AND METHODS}

This study is part of the project "Diptera dos estados do Mato Grosso, Mato Grosso do Sul e Rondônia: diversidade, sistemática e limites distribucionais" (Diptera of the states of Mato Grosso, Mato Grosso do Sul, and Rondônia: diversity, systematics and distributional limits). This project aimed at inventory the diversity of Diptera from Brazil's North and Midwest regions.

The species herein described was collected on May 2012 at Monte Negro municipality, Setor Chacareiro (Linha 25) trail $\left(10^{\circ} 16^{\prime} 21.4^{\prime \prime} \mathrm{S}\right.$, $\left.63^{\circ} 20^{\prime} 45.4^{\prime \prime} \mathrm{W}\right)$, in Rondônia state, Brazil. The gall 
(Fig. 1) was photographed using a digital camera and characterized by the plant organ of occurrence, shape, color, presence or absence of trichomes, and number of internal chambers.

Samples of the host plant were pressed, dried and later sent to Dr. Gracialda Ferreira and Manuel Cordeiro (Universidade Federal Rural da Amazônia - UFRA) for identification. Unfortunately, the Cecropia species was identified up to genus. The exsiccate is deposited in the herbarium of that Institution.

Gall samples were labeled and transported to the laboratory of Diptera (Museu Nacional, UFRJ, Rio de Janeiro). Some galls were placed in plastic pots at room temperature to rear adults. Others were dissected to obtain larvae and pupae of the inducer. The specimens were prepared and mounted on slides following the methods outlined in Gagné (1994).

The gall midge genus was identified using Gagné's (1994) key to Neotropical genera and the species was determined to be new to science after comparison with the original descriptions and illustrations of the known species, and with type specimens from the Cecidomyiidae collection of the Museu Nacional (MNRJ) and from the Museu de Zoologia da Universidade de São Paulo (MZUSP). The diagnostic characters were illustrated with an optical microscope. Photographs were taken by a NIKON eclipse e200 camera coupled to an optical microscope. All drawings were scanned and processed in Autodesk Sketchbook ${ }^{\circledR}$ and Adobe Illustrator CC $2015^{\circledR}$. Both draw's plates and photographs were processed in Photoshop CS6 ${ }^{\circledR}$.

We designated a male as holotype and males, females, pupal exuviae and larvae as paratypes. All material, including the types, is deposited in the Cecidomyiidae collection of Museu Nacional, Rio de Janeiro (MNRJ). Morphological terminology follows Gagné (1994). The field work and gall's photography were done by Carvalho-Fernandes, S.P. and Ascendino, S., all drawings and the species' photograph by Proença, B., and the description of the new species by Proença, B. and Maia, V.C.

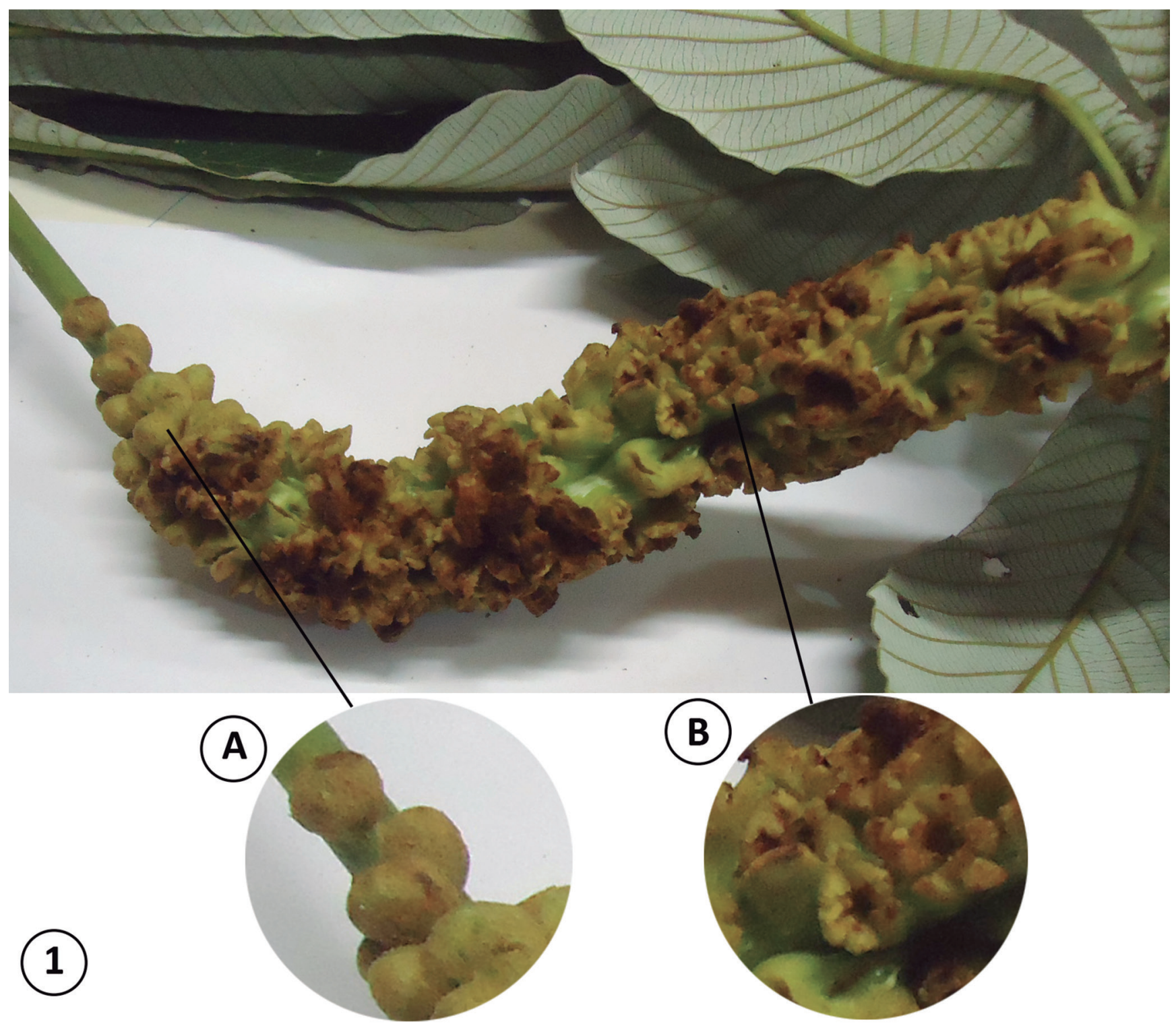

Figure 1. Globoid gall, green, glabrous and one chambered on leaf petiole of Cecropia Loefl. sp. (Urticaceae). (1A) view of the closed gall; (1B) view of the opened gall, showing the inner chamber. 


\section{RESULTS}

\section{Clinodiplosis cecropiae sp. nov.}

(Figs. 2-17)

Diagnose: Adult: palpus one segmented. Occipital process present in both sexes. Tarsal claws simple, and curved near basal third, empodia reaching the bend in claws. Male cerci with oval apex. Gonostylus with half of the length of gonocoxite. Aedeagus triangular, slightly bifurcated at the apex. Pupal exuviae: antennal bases reduced with 0.01-0.02 $\mathrm{mm}$ in length, prothoracic spiracle digitiform and short with 0.1-0.2 mm in length, abdominal segments 2-8 with dorsal spines. Larva: spatula with two triangular teeth, rounded at the apex, slightly divergent; terminal segment: three pairs of corniform papillae, outer pair longer than the others, and one pair setiform.

Description: Adult (Figs. 2-4): Body length: $2.0-2.8 \mathrm{~mm}$ long in males $(n=8), 2.2-3.4 \mathrm{~mm}$ long in females $(n=7)$. Head (Fig. 2): Frontoclypeus with 20-22 setae $(n=9)$. Labrum long-attenuate, with rounded apex and two setae $(n=8)$. Hypopharynx apically setulose, slightly longer than labrum $(n=8)$. Labella with sharp apex, four pairs of setae $(n=8)$. Palpus claviform, one-segmented $(n=15)$. Occipital process in both sexes. Eyes facets hexagonal, all closely approximated. Antenna 2+12: scape cylindrical with three ventral setae at the basal margin $(n=5)$. Pedicel globose with three ventral setae at the apical margin $(n=1)$. Male antennal flagellomeres (Fig. 3 ) binodal and tricircumfilar; internode and neck bare, $5^{\text {th }}$ flagellomere neck about four times shorter than the total length of the flagellomere. Circumfila loops subequals in size. Female flagellomeres cylindrical (Fig. 4), circumfila slightly sinuous, bare neck, neck with one third of the total length of the flagellomere. Male flagellomere 12 with apical process and females with broken antennae.

Thorax (Fig. 5): male wings with 1.7-1.9 $\mathrm{mm}$ in length $(n=5)$, female wings with $2.0-2.3 \mathrm{~mm}$ in length $(n=5)$. Scutum with longitudinal rows of seta, two rows of dorsocentral setae more abundant at the anterior region, simple row of setae from the anterior region to the half of the scutum, two rows of simple lateral setae bare at the mesal portion, one sub-distal row accompanying the margin and some sparse setae. Scutelum bare. Anepimeron with two irregular rows of setae. Anepisternum and other pleura bare. Tarsal claws simple, bent near basal third (Fig. 5).

Male abdomen (Fig. 6): tergites and sternites sclerotized, rectangular, with rounded margins, scales elsewhere, and one pair of trichoid sensillae at the anterior margin. Tergites 1-7 with a row of posterior setae, setae at the lateral margin, and some mesal setae. Tergite 8 not slerotized. Sternite 1-7 with a posterior row of setae, lateral setae, the mesal setae more abundant than those of the tergites. Sternite 8 rectangular, with some setae at the posterior margin.
Male Terminalia (Figs. 7-8): gonocoxite robust, cylindrical, setulose, with mesal setae irregularly distributed in all extension, with a discrete mesobasal lobe. Gonostylus with half the gonocoxite's length, fusiform, setulose, covered with setae, teeth strongly sclerotized, with ventral group of papillae on basal portion (Fig. 8). Cerci wide, with oval margin, setulose, with several apical setae. Hypoproct deeply bilobed, slightly shorter than cerci, setulose, with setae concentrated at the apex. Aedeagus triangular, slightly bifurcated apically, wider than cerci, with slight roughness at distal half, with asetose ventrolateral papillae.

Female abdomen (Fig. 9): Tergites and sternites sclerotized, rectangular, with rounded margin, one pair of trichoid sensillae at the anterior margin, scales elsewhere. Tergites 1-7 rectangular, with a posterior row of setae. Tergite 8 not sclerotized, with a row of posterior setae. Sternites 1-7 with a row of posterior setae, lateral and mesal setae. Sternite 8 not sclerotized, with some sparse setae.

Ovipositor (Fig. 10): short, slightly protrusible, subequal in length to sternite 7, cerci separated, semicircular, setulose, with sparse dorsal setae longer and more abundant than the ventral setae. Hypoproct cylindrical, setulose, with few apical setae.

Pupal exuviae (Figs. 11-14): 2.2-3.1 $\mathrm{mm}$ in length $(n=15)$. Cephalic region (Fig. 11): a pair of cephalic seta short, with $0.01 \mathrm{~mm}$ in length $(n=4)$ and a pair of asetose papilla. Antennal bases short, with $0.01-0.02 \mathrm{~mm}$ in length $(n=10)$. Upper cephalic margin thickened laterally. Two pairs of lower facial papillae: one asetose and one setose. Lateral facial papillae not visible.

Thorax: Prothoracic spiracle digitiform, short, with $0.1-0.2$ in lenght $(n=4)$. Wings sheath reaching the median portion of abdominal segment 3; fore legs shorter than the others, reaching the anterior $1 / 4$ of the abdominal segment 3; fore and mid legs reaching at the basal margin of abdominal segment 3 .

Abdomen (Fig. 12): Spiny integument. Segments 2-8 with spines concentrated only at basal third. Terminal segment with a pair of corniform horns, strongly sclerotized, bent in males (Fig. 13) and straight in females (Fig. 14).

Third instar larva (Figs. 15-17): length: 1.8-2.4 mm $(n=5)$. Fusiform body, rough integument (Fig. 15). Spatula sclerotized (Fig. 16), with 0.20-0.22 mm in length $(n=3)$, two toothed, triangular teeth rounded at the apex, slightly separated from each other. Spatula shaft developed, with truncate base. One asetose pair of sternal papillae. Three pairs of lateral papillae on each side of spatula: one asetose and two setose. Terminal segment (Fig. 17) with three pairs of corniform papillae, outer pair longer than the others, and one pair of setiform papilla with 0.05-0.6 mm in length $(n=4)$. Ventral anus. 

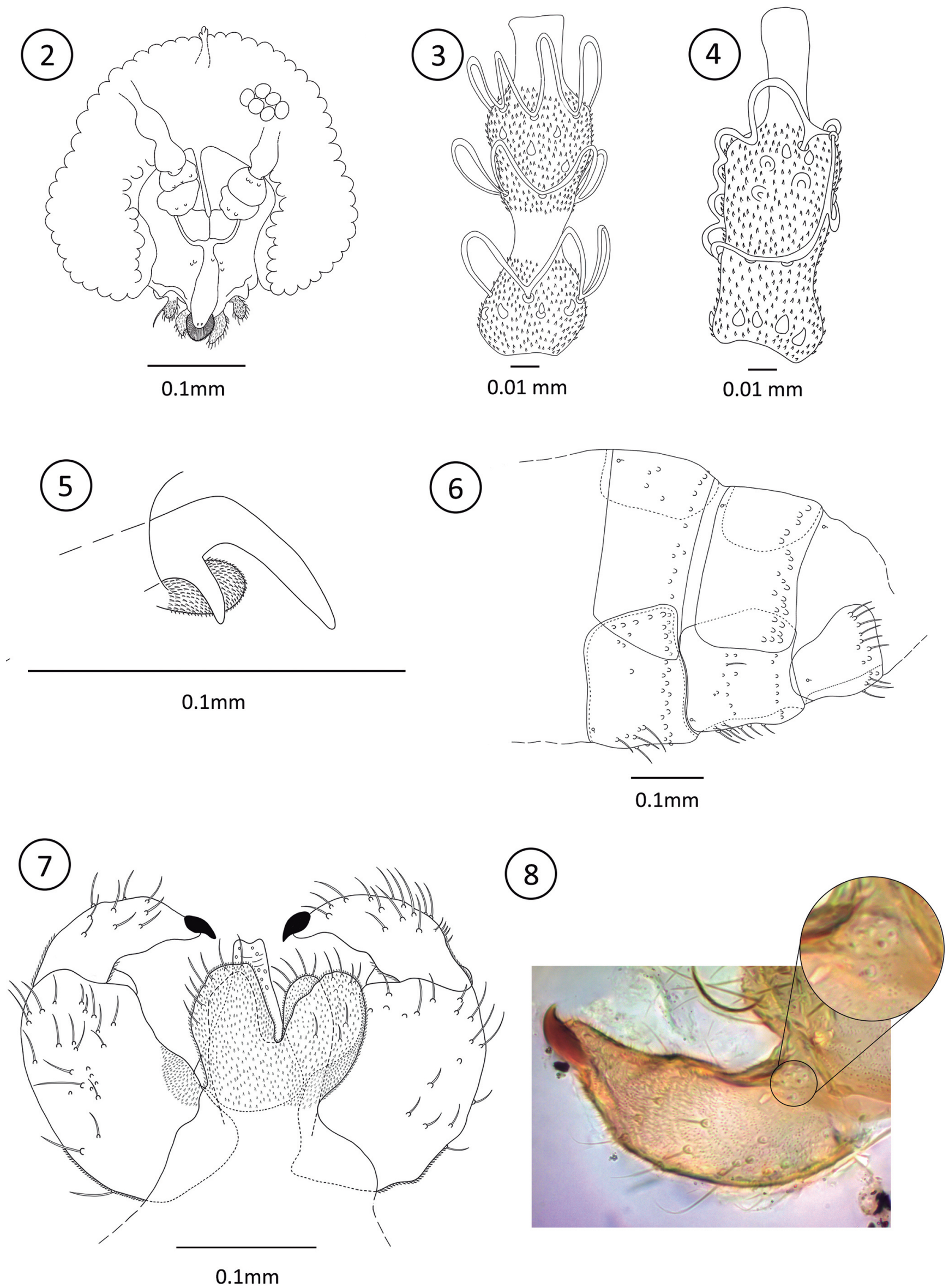

Figures 2-8. Clinodiplosis cecropiae Proença \& Maia. (2) male head (frontal view); (3) male flagellomere V; (4) female flagellomere V; (5) female fore leg: claws and empodium (lateral view); (6) male abdomen, segments 6-8 (lateral view); (7) male terminalia (dorsal view); (8) detail of the male's gonostylus showing the group of papillae the basal portion (ventral view) (100x). 

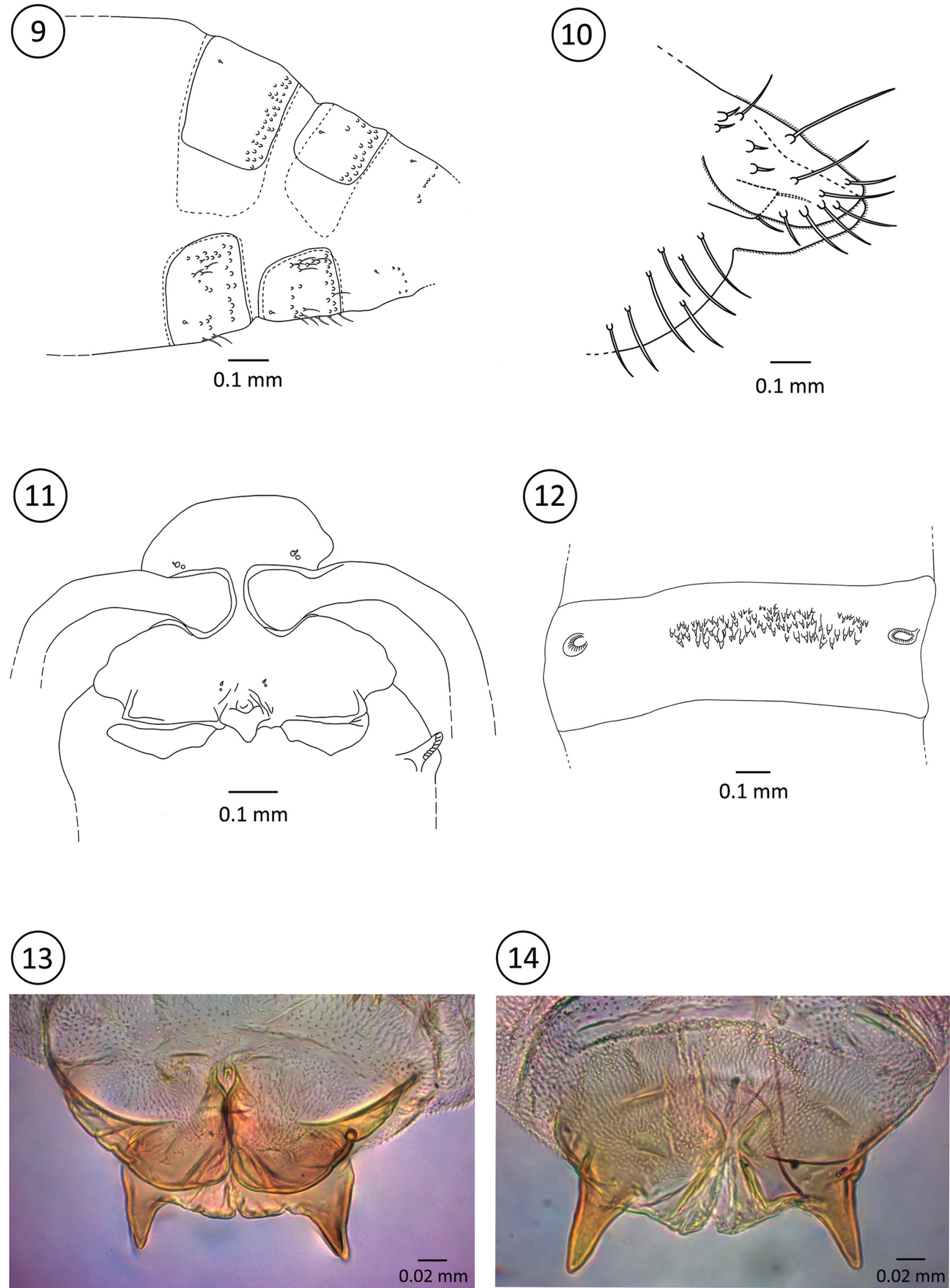

Figures 9-14. Clinodiplosis cecropiae Proença \& Maia. (9) female abdomen, segments 6-8 (lateral view); (10) ovipositor (lateral view); (11) pupal exuviae: cephalic region and prothoracic spiracle (frontal view); (12) pupal exuviae: abdominal segment $V$ (dorsal view); (13-14) sexual dimorphism on pupal exuviae: (13) male's pupal exuvia: terminal segment; (14) female's pupal exuvia: terminal segment. 
Host plant: Cecropia Loefl. sp. (Urticaceae).

Gall: on leaf petiole, globoid, green, glabrous and one chambered.

Etymology: the specific name cecropiae refers to Cecropia, the genus' name of the host plant.

Associated fauna: four larvae were identified as Diadiplosis Felt, 1911, a genus known for its predatory habit.

Material examined: Holotype: BRAZIL: $\sigma^{\top}$ (with 12 flagellomeres on one side and two on the other), North Brazil,
Rondônia, Monte Negro municipality, Setor Chacareiro (Linha 25) trail, $10^{\circ} 16^{\prime} 21.4^{\prime \prime} \mathrm{S}, 63^{\circ} 20^{\prime} 45.4^{\prime \prime} \mathrm{W}$, 17.May.2012, Carvalho-Fernandes, S.P. and Ascendino, S. col., Cecropia Loefl. sp. (Urticaceae), (MNRJ). Paratypes: BRAZIL: North Brazil, 8 ơ $^{\prime}$ (two with missing antennae, six with antennae broken: two with two flagellomeres; two with two flagellomeres on one side and none on the other; one with three flagellomeres on one side and two on the other; and one with three flagellomeres in both sides. 9 \%o (five with antennae missing, four with antennae broken: one with four flagellomeres; one with five flagellomeres on one side and none on the other; one with two flagellomeres on one side and none on the other; and one with a single flagellomere on one side and none on the

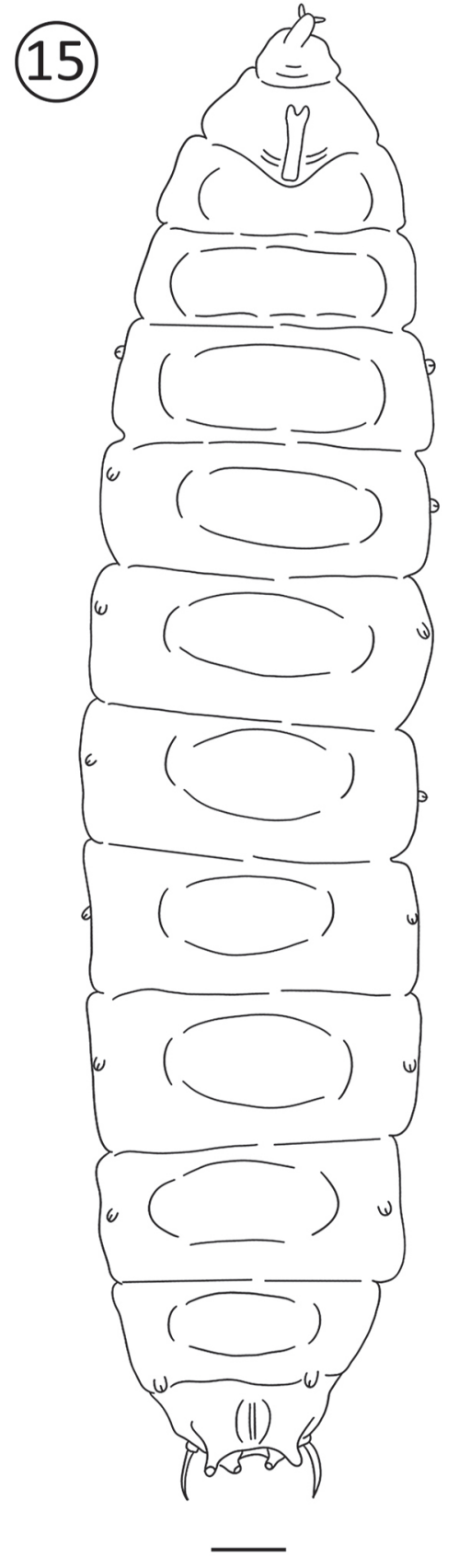

$0.1 \mathrm{~mm}$
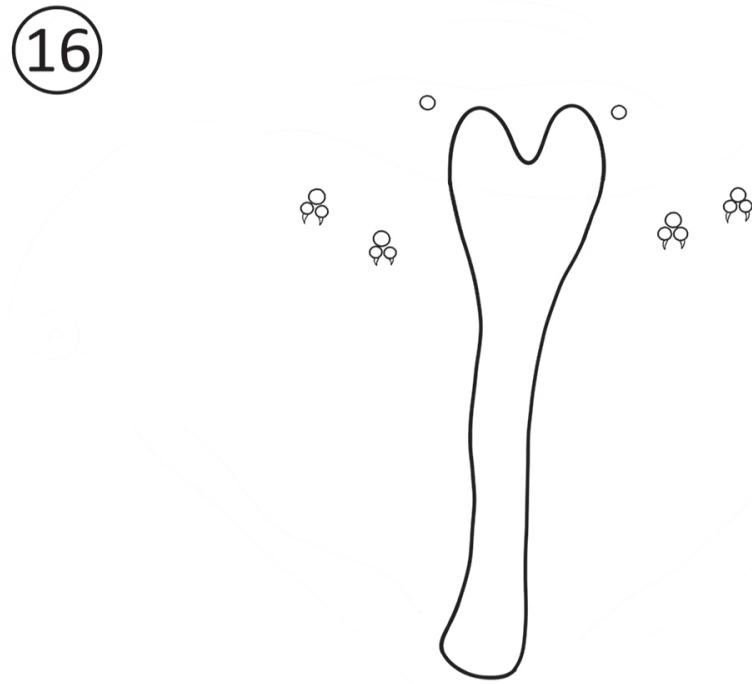

$0.1 \mathrm{~mm}$

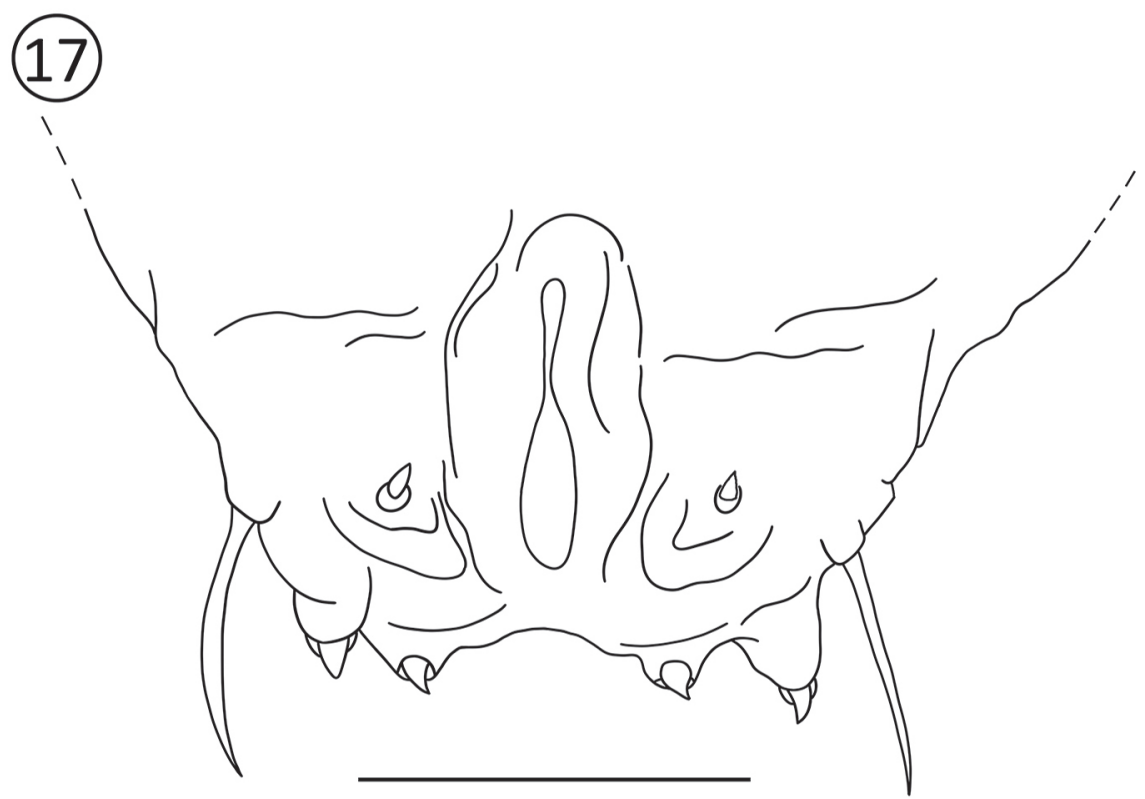

$0.1 \mathrm{~mm}$

Figures 15-17. Clinodiplosis cecropiae Proença \& Maia. (15) larva, general aspect (ventral view); (16) larval spatula and lateral papillae (ventral view); (17) larva: terminal segment (ventral view). 
other), 15 pupal exuviae and 7 larvae, same locality and collectors (MNRJ).

Remarks: This species was included in Clinodiplosini tribe based on the morphology of the larval terminal papillae: three corniform (one shorter than the rest) and one setiform. This terminal papillae arrangement is exclusive to Clinodiplosini, and among all the genera present in the tribe, Clinodiplosis is the most heterogeneous, with adults varying in several aspects such as tarsal claws aspects and empodia length. The males can have varied aedeagus and cerci shape. The other Neotropical genera have exclusive characters as well as basal constrained gonostylus (Houardodiplosis Tavares, 1925), male hypoproct with recurve lobe (Iatrophobia Rübsaamen, 1916) and female $10^{\text {th }}$ tergum with setae (Schismatodiplosis Rübsaamen, 1916). None of these conditions are found in Clinodiplosis species.

The new species is unique among the other Clinodiplosis by presenting one segmented palpus. All adults of the Clinodiplosini tribe, including the Clinodiplosis species, have four segmented palpus.

This species is morphological similar to Clinodiplosis melissae Maia, 1993 because both have the same following characteristics: simple claws; loop of the distal circumfila not trespassing the flagellomere's neck; female with similar cerci shape; pupa with simple and short antennal bases; and larval setiform terminal papillae with similar length. Both species attack the leaves of their host plants; C. melissae induces galls on the leaf's surface of Melissa officinalis L. (Labiatae), while C. cecropiae induces galls on leaf petioles of Cecropia sp. (Urticaceae).

However, these two species differ in the following aspects: prothoracic spiracle and apical setae clearly longer in C. melissae than in the new species. In C. cecropiae the male cerci are longer than the hypoproct and the aedeagus is triangular with a small depression at the apex, whereas in males of $C$. melissae the cerci are much shorter than the hypoproct and the aedeagus is slender, with rounded apex.

In Brazil, there are 17 known species of Clinodiplosis in 12 host plants families, being more frequent on
Asteraceae (Gagné \& Jaschhoff, 2017). Besides the new species, there is another species of Cecidomyiidae inducing galls on Urticaceae in the Neotropics: Cecidomyia cecropiae Cook, 1909, collected on Cecropia obtuse Trécul, Ann., in Cuba. Seven other species have been described in association with this same plant family throughout the world, three are Palearctic, Ametrodiplosis urticae Kovalev, 1972, Dasineura dioicae (Rübsaamen, 1895), Dasineura urticae (Perris, 1840), two are Oriental, Schizomyia laporteae Felt, 1921 and S. villebrunneae Felt, 1921 and two are Nearctic, Dasineura urnicola (Osteb Sacken, 1875) and Neolasioptera bochmeriae (Beutenmüller, 1908). This is the first record of Clinodiplosis on Urticaceae.

\section{ACKNOWLEDGMENTS}

We thank to Sharlene Ascendino and Sheila Patrícia Carvalho-Fernandes for the field work and all the researchers involved on the Sisbiota Diptera project. This study was supported by CNPq (Conselho Nacional de Desenvolvimento Científico e Tecnológico, Proc. 563256/2010-9).

\section{REFERENCES}

Cornelis, C.B.; Rosselli, P.F. \& Davidson, D.W. 2005. Cecropia. Flora Neotropica, 94: $1-230$.

Flora do Brasil. 2020. [em construção]. Jardim Botânico do Rio de Janeiro. Available at: http://floradobrasil.jbri.gov.br. Access in: 10/05/2019.

Gagné, R.J. 1994. The Gall Midges of the neotropical region. Ithaca, N.Y., Cornell University Press.

Gagné, R.J. \& Jaschhof, M. 2017. A catalog of the Cecidomyiidae (Diptera) of the world. 4.ed. Digital. Available at: https://www.ars.usda.gov/ ARSUserfiles/80420580/Gagne 2017 World Cat 4th ed.pdf. Access in: 06/05/2019.

Toma, T.S.P. \& Maia, V.C. 2012. Representatividade do gênero Clinodiplosis Kieffer (Diptera, Cecidomyiidae) no Brasil. Papéis Avulsos de Zoologia, 52: 223-231. 